\title{
Activity of loggerhead turtles during the U-shaped dive: insights using angular velocity metrics
}

\author{
Richard M. Gunner ${ }^{1, *}$, Rory P. Wilson ${ }^{1}$, Mark D. Holton ${ }^{1}$, Rebecca Scott ${ }^{2,3}$, \\ Alex Arkwright ${ }^{1,4}$, Andreas Fahlman ${ }^{4}$, Marie Ulrich ${ }^{5}$, Phil Hopkins ${ }^{1}$, Carlos \\ Duarte $^{6}{ }^{6}$ Christophe Eizaguirre ${ }^{7}$
}

\begin{abstract}
${ }^{1}$ Swansea Lab for Animal Movement, Biosciences, College of Science, Swansea University, Swansea SA2 8PP, UK ${ }^{2}$ GEOMAR Helmholtz Centre for Ocean Research, Kiel, Düsternbrooker Weg 20, 24105 Kiel, Germany ${ }^{3}$ Natural Environmental Research Council, Polaris House, North Star Avenue, Swindon SN2 1FL, UK ${ }^{4} L^{\prime}$ Oceanogràfic, Ciutat de les Arts i de les Ciències, Carrer d'Eduardo Primo Yúfera, 1B, 46013 Valencia, Spain ${ }^{5}$ Institutionen för fysik kemi och biologi (IFM), Linköping Universitet, Olaus Magnus väg, 58330 Linköping, Sweden ${ }^{6}$ Red Sea Research Centre, King Abdullah University of Science and Technology (KAUST), Thuwal 23955, Saudi Arabia ${ }^{7}$ School of Biological and Chemical Sciences, Queen Mary University of London, London E35SA, UK
\end{abstract}

\begin{abstract}
Understanding the behavioural ecology of endangered taxa can inform conservation strategies. The activity budgets of the loggerhead turtle Caretta caretta are still poorly understood because many tracking methods show only horizontal displacement and ignore dives and associated behaviours. However, time-depth recorders have enabled researchers to identify flat, Ushaped dives (or type 1a dives) and these are conventionally labelled as resting dives on the seabed because they involve no vertical displacement of the animal. Video- and acceleration-based studies have demonstrated this is not always true. Focusing on sea turtles nesting on the Cabo Verde archipelago, we describe a new metric derived from magnetometer data, absolute angular velocity, that integrates indices of angular rotation in the horizontal plane to infer activity. Using this metric, we evaluated the variation in putative resting behaviours during the bottom phase of type 1a dives for 5 individuals over 13 to $17 \mathrm{~d}$ at sea during a single inter-nesting interval (over 75 turtle $\mathrm{d}$ in total). We defined absolute resting within the bottom phase of type 1 a dives as periods with no discernible acceleration or angular movement. Whilst absolute resting constituted a significant proportion of each turtle's time budget for this 1a dive type, turtles allocated 16-38\% of their bottom time to activity, with many dives being episodic, comprised of intermittent bouts of rest and rotational activity. This implies that previously considered resting behaviours are complex and need to be accounted for in energy budgets, particularly since energy budgets may impact conservation strategies.
\end{abstract}

KEY WORDS: Animal behaviour - Angular velocity - Accelerometer - Caretta caretta Dive type Magnetometer

\section{INTRODUCTION}

Sea turtles spend almost all of their lives at sea, which creates difficulties collecting data that may be relevant to their conservation (Gilman et al. 2007, Hochscheid 2014, Wallace et al. 2015, Butt et al. 2016, Mingozzi et al. 2016). This is particularly true with respect to behaviours associated with space use and en-

${ }^{*}$ Corresponding author: richard.m.g@hotmail.com ergy expenditure (López-Sepulcre 2007, Greggor et al. 2016). However, animal-attached logging devices have provided researchers with a powerful tool to record patterns of behaviour, even when turtles are underwater. A tag commonly used for this purpose is the time depth recorder (TDR) (Hays et al. 2007, Hart et al. 2010, Wilson et al. 2017, Dodge et al. 2018), which provides information on depth use over time,

(C) The authors 2021. Open Access under Creative Commons by Attribution Licence. Use, distribution and reproduction are unrestricted. Authors and original publication must be credited. 
from which dive profiles can be reconstructed (Eckert et al. 1986, Hays et al. 2002b, Rice \& Balazs 2008).

These dive profiles have been broadly classified into 5 or 6 distinguishable types through their marked repetition and consistent patterns (Minamikawa et al. 1997. Hochscheid et al. 1999, Hays et al. 2000, Houghton et al. 2002, Hochscheid 2014, Wilson et al. 2017). Different dive types are hypothesized to reflect changes in behavioural motivation and associated activity levels (Hochscheid 2014). For example, 'type 1a' dives, flat U-shaped dives, are very common among sea turtles (Hochscheid et al. 2007, Cheng 2009), and are typically associated with resting (Hays et al. 2000, Seminoff et al. 2006, Hays 2008, Cheng 2009, Okuyama et al. 2012). These dives are more prevalent between nesting events, at times when turtles are reported to be minimizing energy expenditure so as to allocate resources to developing eggs (Houghton et al. 2002, Schofield et al. 2009). Indeed, classification of these dives as resting behaviour is important, particularly because of their potential role in saving energy for turtles, which are considered to be primarily 'capital' breeders (Jönsson 1997, Bonnet et al. 1998, Plot et al. 2013). But evidence that type 1a dives in inter-nesting female turtles are genuinely just resting dives is equivocal: Hochscheid et al. (1999) suggested that turtles might forage during the dive, and Myers \& Hays (2006) explicitly noted beak movements in internesting leatherback turtles Dermochelys coriacea during various dives that also implied foraging in nesting areas. There is thus a need for further information on the activities of female turtles during the inter-nesting phase to determine the extent to which type 1a dives might be associated with foraging in nesting areas. Such information may be important for conservation initiatives, which may have to consider protecting the space used by inter-nesting females rather than considering it energetically barren.

TDRs, however, lack the resolution to detect specific behaviours beyond changes in depth and therefore the ability to determine the extent to which turtles may be foraging is limited using this approach. Seminoff et al. (2006) addressed this issue using video recorders integrated with TDR technology (VTDRs) mounted onto the carapaces of (non-nesting) green turtles Chelonia mydas. From their observations, they concluded that a suite of behaviours can be expressed within a single dive profile, noting that time-depth plots for determining underwater behaviours should therefore be treated with caution. Type 1a dives, for instance, consisted of both continuous and episodic resting behaviour. Furthermore, horizontal movements and stationary and active benthic feeding were prevalent during the bottom phase of this dive type. Although illuminating, animal-attached video recording systems are power and memory hungry and so can only operate continuously for a few hours during daylight (Park et al. 2019).

Another approach to elucidate turtle behaviour is the deployment of high frequency tri-axial accelerometers which can be used over extended period (e.g. Narazaki et al. 2009, Hussey et al. 2015, Wilmers et al. 2015). Accelerometers have been used to link dive profiles with underwater activities in the context of buoyancy regulation, depth utilisation and the dynamism of movement (Hays et al. 2007, Fossette et al. 2010, Parlin et al. 2018). However, turtles can spend large portions of their behavioural time budget gliding at relatively constant velocity (Wyneken 1997, Walker \& Westneat 2000, Martin 2003), especially during the bottom phase of type 1a dives, which produces little or no change in the acceleration, making interpretation of behaviours problematic (Eckert 2002, Wilson et al. 2020a).

The lack of dynamism in some turtle activities can be addressed, in part, by examining various scales of angular body rotations over time, which can reveal patterns of movement (Noda et al. 2012) beyond those imparted by the dynamism in body acceleration (Gunner et al. 2020). This concept was introduced by Hochscheid \& Wilson (1999), who quantified activity patterns via a compass system using a miniature, fluid-filled ship's compass with 2 magnetic field (Hall) sensors on the sphere's equator. These sensors are particularly sensitive to changes in individuals' horizontal orientation (changes in animal yaw) and Hochscheid et al. (1999) demonstrated how this approach could be used to produce an activity index for 2 free-living green turtles. Although their system did not allow for precise calculation of angular velocities or defined angular extents, it is, to our knowledge, the only study that quantifies the behavioural time budget of common type 1a dives over whole inter-nesting intervals.

Here, we assess the extent to which angular rotation can quantify the activity of 5 wild loggerhead turtles Caretta caretta engaged in type 1a dives between nesting events. Specifically, we deployed tags which recorded tri-axial acceleration and triaxial magnetic field intensity, both of which can be recorded over periods of many days (cf. Brown et al. 2013). These allowed us to estimate the angular velocity of all 3 axes of rotation (pitch, roll and yaw), and combine them into an overall absolute angular velocity (AAV) proxy to infer activity. We also used 3 captive loggerhead turtles to ground truth our 
data. Beyond indicating that turtles might be feeding, angular velocity is relevant to nesting turtles because body rotation is energetically expensive (Wilson et al. 2020a,b), with the power costs projected to rise with increasing angular extent and velocity (A. M. Wilson et al. 2013, J. W. Wilson et al. 2013). Precise quantification of the extent of activities should therefore help us understand power and energy management in turtles during this critical phase of their lives.

\section{MATERIALS AND METHODS}

\subsection{Subjects, study area and tagging}

Five mature female loggerhead turtles were equipped with daily diary (DD) logging units (cf. Wilson et al. 2008) enclosed in a square silicone casing and attached, using an epoxy resin, by placing them flat against the shell, usually between the first and second scute. Tri-axial acceleration (range: $\pm 16 g$ ) and tri-axial magnetic field intensity (recorded in G at $0.73 \mathrm{mG} \mathrm{LSB}^{-1}$ [milligauss per least significant bit, cf. Tuck 2010] resolution, range: $\pm 0.88 \mathrm{G}$ ) data were recorded at $40 \mathrm{~Hz}$, while pressure was recorded at $4 \mathrm{~Hz}$ to provide depth information. Devices were deployed only on nesting turtles after egg deposition, to minimize disruption and stress. All devices were deployed on a single beach in the south of Boa Vista island, Cabo Verde (Cameron et al. 2019), over a period of 8 nights starting on 22 July 2014. Turtles also received a passive integrated transponder to identify them in case they were seen again without the DD units. All tags were retrieved when the turtles returned after a single inter-nesting interval, either on the beach of deployment or on adjacent beaches.

Three female adult captive turtles housed at the Arca del Mar rehabilitation centre in Oceanografic in Valencia were also fitted with DD loggers intermittently between June and August 2018. Data was recorded at $20 \mathrm{~Hz}$. Turtles undergoing rehabilitation were housed in separate circular tanks, $6 \mathrm{~m}$ in diameter, with a water depth of $0.95 \mathrm{~m}$. These turtles were observed at intervals (between 10 and $60 \mathrm{~min}$ ) and results obtained were used solely to ground truth an absolute angular velocity metric (see later) by ascertaining that high values of absolute angular velocity corresponded to periods when turtles exhibited high turning rates.

Custom-designed software; Daily Diary Multi Trace (DDMT, www.wildbytetechnologies.com), was used to visualise DD data, create the appropriate channel smoothing windows, extract differentials and implement Boolean-type, time-based behavioural expressions linked to the dive depths at which type 1a dives occurred. R (version 3.51, www.r-project.org) and OriginPro 2016 (OriginLab Corporation, www. originlab.com/) were used for further statistical and graphical analysis. Google Earth (www.google.com/ earth) was used to perform polygon transects to approximate the seabed elevation profile as a function of distance from the coastline of the nesting beach. Ethical approval was obtained from the Oceanogràfic Animal Care \& Welfare Committee (OCE-16-18) for the captive turtles and authorisations were obtained from the Direção Geral do Ambiente (DGA 30/2013) for the wild animals.

\subsection{Derivation of angular velocity}

All stages involved in the derivation of pitch, roll and compass heading (using tri-axial accelerometers and magnetometers) are detailed in Ozyagcilar 2012, Pedley 2012, 2013, and Gunner et al. 2020.

All 3 indices of derived body rotation (pitch, roll and yaw) were pre-smoothed using a rolling window of $2 \mathrm{~s}$ to eliminate small deviations due to noise stemming from the flipper beat cycle. A circular mean was used for yaw (Pewsey et al. 2013). Each complete set of data taken from an individual turtle was subsequently subsampled to $1 \mathrm{~Hz}$ to facilitate computation.

AAV was derived using data from both the accelerometers and magnetometers (Gunner et al. 2020). AAV is calculated from the integration of each rotational axis' instantaneous angular velocity measurement and given by

$$
\mathrm{AAV}=|\mathrm{AveP}|+|\mathrm{AVeR}|+|\mathrm{AVeY}|
$$

where the differentials AVeP, AVeR and AVeY (angular velocity about the pitch, roll and yaw axis, respectively) were calculated in ${ }^{\circ} \mathrm{s}^{-1}$ using a stepping range of $1 \mathrm{~s}$ (Gunner et al. 2020). A logical expression was implemented on the derivative $\mathrm{AVeY}$ to ensure rate of change never exceeded $180^{\circ} \mathrm{s}^{-1}$ (Wilson et al. 2008) to determine whether the rotation was clockwise or anti-clockwise.

The vectorial dynamic body acceleration (VeDBA) was also calculated following the protocols outlined by Qasem et al. (2012). To calculate VeDBA, the dynamic acceleration of each axis was derived by subtracting the smoothed (static) acceleration from the raw data before taking the vectorial sum of the dynamic accelerations. 


\subsection{Depiction of type 1a dives and activity}

The DD also records pressure (mbar), which was used to determine diving depth in $\mathrm{m}$ (see equations in Wilson et al. 1992). Baseline offsets of recorded pressure were accounted for and a further $10 \mathrm{~cm}$ buffer depth offset was implemented, less than or equal to the corrected depth at the surface (essentially $10 \mathrm{~cm}$ less than or equal to $0 \mathrm{~m}$ depth), before depth was computed. Only dives with (at least part of) a bottom phase greater than or equal to $3 \mathrm{~m}$, (termed deep dives;

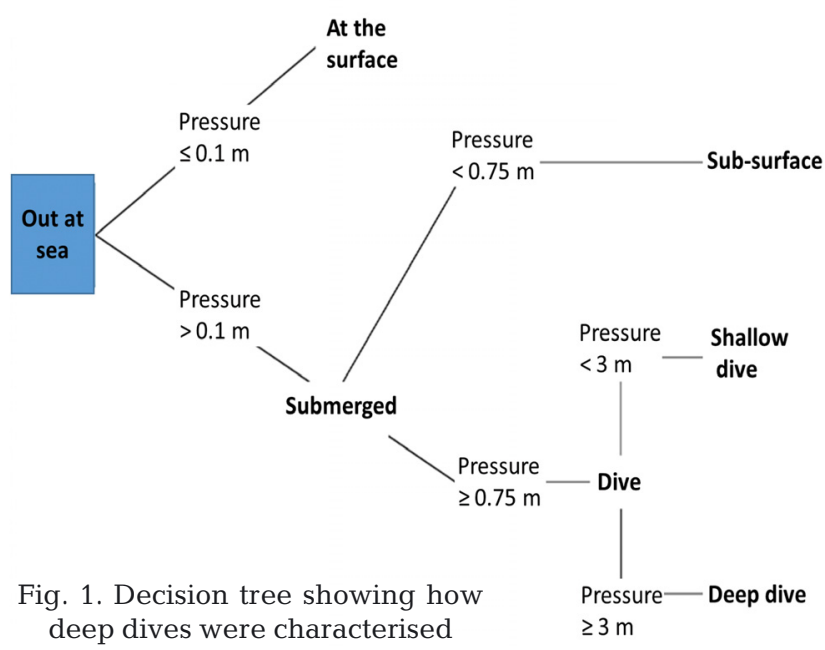

Fig. 1) were categorised by dive type, because relative variation in depth at shallower depths was higher due to the effect of waves (cf. Houghton et al. 2002). Type 1 a dives were identified based on 3 criteria:

(1) The general shape of the dive profile consisted of steep descent and ascent phases with a flat bottom between (Fig. 2);

(2) the pressure differential (calculated over $10 \mathrm{~s}$; pressure pre-smoothed by $2 \mathrm{~s}$ ) exceeded a defined threshold of \pm 0.03 mbar during periods of descent and ascent ( $0.03 \mathrm{~m} \mathrm{~s}^{-1}$ differential depth [vertical speed], as previously determined and proposed by Hays et al. [2000]) and

(3) over the duration of the bottom phase, change in depth did not exceed $1 \mathrm{~m}$ from the base line.

Only the bottom phase of type 1a dives were assessed. Video recordings of captive turtles were taken to ground truth whether AAV was an accurate reflection of activity extent observed directly. To stimulate appreciable activity, turtles were provided with a food source (jellyfish). Despite relatively restricted movements due to tank confinement, clear differences were noted between actively swimming, manoeuvring along the bottom and complete rest periods. Activity resulted in periods of AAV exceeding $5^{\circ} \mathrm{s}^{-1}$, while only continuous bouts of rest coincided with constant values of AAV below $3^{\circ} \mathrm{s}^{-1}$ (the limit of resolution of the system). This contrasting pattern was ap-

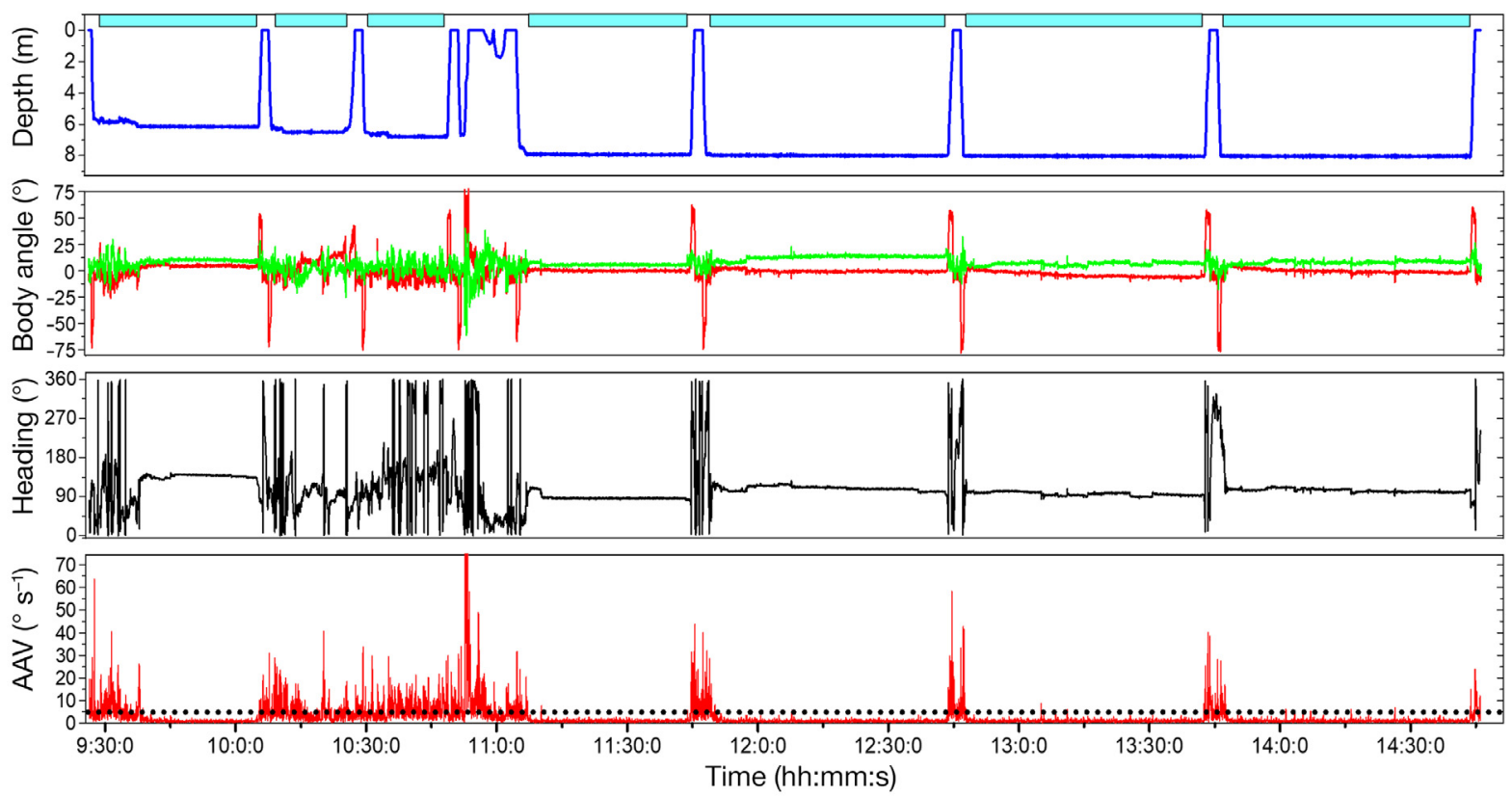

Fig. 2. An example of a continuous bout of diving behaviour (approx. $5.5 \mathrm{~h}$ ) from a wild loggerhead turtle. Bottom phase of type 1a dive denoted with cyan blocks (top). Rest periods are inferred by continuous bouts of relatively unchanging body rotation (red: pitch, green: roll, black: yaw [heading]). Note, heading is plotted in a different panel to pitch and roll because its range of measurement range is higher. Absolute angular velocity (AAV) periods during bouts of active swimming and remains consistently low during rest periods. The threshold of $5^{\circ} \mathrm{s}^{-1}$ for AAV is denoted with a black dotted line 
parent during visual inspection of the sensor data from free-ranging turtles (Fig. 2).

The topographic conditions associated with wild turtles resting were taken into consideration. Turtles do not always rest on a hard substrate; they have also been reported to rest on fauna (corals), flora (algae) and in the open with no apparent holdfasts. Thus, they are subject to motion from current vectors (Okuyama et al. 2010). To account for this additional degree of possible sensor noise a slightly higher threshold of $5^{\circ} \mathrm{s}^{-1}$ was implemented for AAV, below which the animals were considered to be at absolute rest. However, even during periods of low activity, e.g. stationary foraging or slow rates of movement, intermittent values above the threshold were apparent. To account for those effects, 2 time-based criteria were implemented, both of which had to be met for a resting bout to be marked as such:

(1) AAV had to remain below $5^{\circ} \mathrm{s}^{-1}$ for a minimum of $30 \mathrm{~s}$

(2) During a rolling window of $30 \mathrm{~s}$, the extent of a turn could not exceed $45^{\circ}$.

A resting bout was thus marked until one or both criteria were no longer met. Marked resting periods within $5 \mathrm{~s}$ of each another were merged, since a very brief change in orientation does not necessarily correspond to activity (Hochscheid \& Wilson 1999). Periods not marked as resting were active. Finally, depending on the proportion of bottom phase attributed to periods of marked rest, type 1a dives were subclassified as being predominantly resting (resting $\geq 80 \%$ ), episodic-resting (resting between 20 and $80 \%$ ) or active (resting $\leq 20 \%$ ). This subclassification is referred to hereafter as dive status.

\subsection{Statistical analyses}

A linear mixed model (LMM) was performed using the lmer function in $\mathrm{R}$, from the lme4 package (Bates et al. 2015), to determine the extent to which dive duration correlated with AAV and dive depth (mean values per type 1a dive pooled into one grand mean value for each turtle). Turtle ID was set as a random factor. Diagnostic plots of the residuals revealed a departure from linearity and homoscedasticity. As such, box-cox transformation analysis from the MASS package was used to assess the appropriate exponent $(\lambda=1)$ with which to transform data; the natural $\log$ of the independent variables (AAV and depth) was used. The model simplification method (forward selection) was employed using likelihood ratio tests with an ANOVA function. Due to the ap- parent non-linear relationship between untransformed variables, a generalized additive mixed effects model (GAMM; mgcv package, using thin plate regression splines $(\mathrm{k}=7$ ) and a smoothing function) was also constructed for comparison.

To infer the metabolic costs associated with dives and angular velocity, we used the approximation that zero AAV corresponded to resting metabolic rate (RMR). Under the condition that zero AAV approximately corresponds to RMR, dives with zero angular velocity throughout the bottom phase were approximately 40 min in duration (see Fig. 6A). Based on this approximation, we constructed the putative curve of metabolic costs associated with AAV (expressed as a multiple of RMR) by dividing 40 min by the dive duration predicted based on AAV (using the predict.gam function in $\mathrm{R}$ ).

\section{RESULTS}

Overall, we analysed a total of 75 turtle d, with individuals spending between 13 and $17 \mathrm{~d}$ at sea (mean $( \pm \mathrm{SD}) 15 \pm 1.6 \mathrm{~d})$. Weather conditions during the study (as reported every $3 \mathrm{~h}$ by a nearby station in Curral Velho) varied appreciably, such as wind (9-39 $\mathrm{km} \mathrm{h}^{-1}$, typically coming from the northeast),

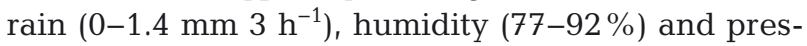
sure (1012-1018 mb), though temperature remained relatively constant $\left(23-25^{\circ} \mathrm{C}\right)$.

There were large inter-individual differences in the proportion of time spent at different depths (Fig. 3A). Type 1a dives were frequent and represented between 40 and $61 \%$ of the total number of deep dives ( $>3 \mathrm{~m}$, Fig. 3A,B), despite the total number of deep dives differing substantially among turtles (Table 1). Depths during type 1a dives were generally quite shallow, with only 1 turtle exceeding a depth of $11 \mathrm{~m}$ (Fig. 3C, Table 1, see Fig. S1 in the Supplement at www.int-res.com/articles/suppl/n045p001_supp.pdf for approximate bathymetry estimates around the nesting site). The duration of this dive type varied considerably for each turtle (Table 1).

We noted large variations in the mean VeDBA estimates (mean value per type 1a dive pooled into one grand mean value for each turtle) between turtles, ranging from 0.037 to $0.096 \mathrm{~g}$, with a coefficient of variation $(\mathrm{CV})$ of $36.95 \%$. Equivalent AAV offsets appeared much lower, ranging from 2.851 to $3.902^{\circ}$ $\mathrm{s}^{-1}$, with a CV of $13.05 \%$. In terms of angular velocity, higher rates of activity were indicated by higher estimates of $\mathrm{AVeR}, \mathrm{AVeP}$ and $\mathrm{AVeY}$ and typically included appreciable components from all 3 rotation 

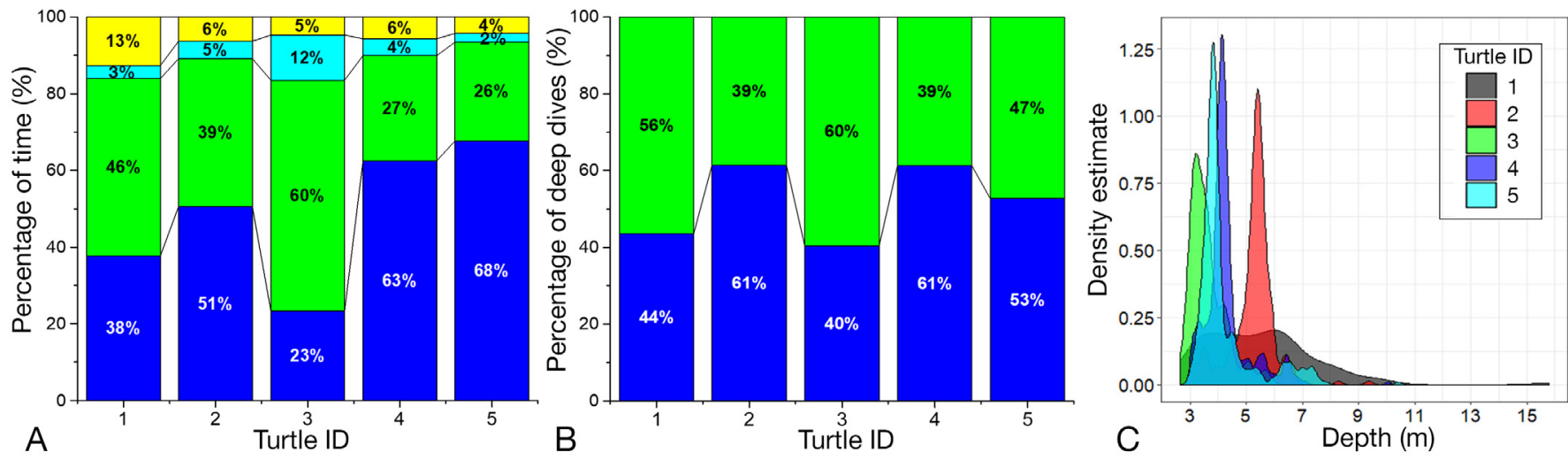

Fig. 3. (A) Time budget of depth use by 5 female loggerhead turtles while out at sea. Blue: deep dive, green: shallow dive, cyan: sub-surface swimming, yellow: surface. (B) Percentage of deep dives defined as type 1a. Blue: type 1a, green: other. (C) Relative density of depths obtained during type 1a dive bottom phase, coloured according to turtle ID

Table 1. Number of type 1a dives (vs. total number of deep dives in parentheses) and mean $( \pm \mathrm{SD})$ number per day, maximum depth and duration of this dive type for each tracked turtle

\begin{tabular}{|lcccc|}
\hline Turtle ID & $\begin{array}{c}\text { Count (Total count } \\
\text { of deep dives) }\end{array}$ & Daily mean & Depth (m) & Duration (min) \\
\hline 1 & $122(280)$ & $8.13 \pm 5.15$ & $5.48 \pm 1.93$ & $34.43 \pm 18.05$ \\
2 & $255(415)$ & $17.0 \pm 6.75$ & $5.24 \pm 0.79$ & $31.67 \pm 16.05$ \\
3 & $76(184)$ & $5.85 \pm 3.83$ & $3.65 \pm 0.61$ & $22.01 \pm 14.71$ \\
4 & $419(684)$ & $23.28 \pm 10.62$ & $4.32 \pm 0.84$ & $27.65 \pm 16.20$ \\
5 & $400(758)$ & $25.0 \pm 10.39$ & $4.26 \pm 1.11$ & $25.52 \pm 17.96$ \\
\hline
\end{tabular}

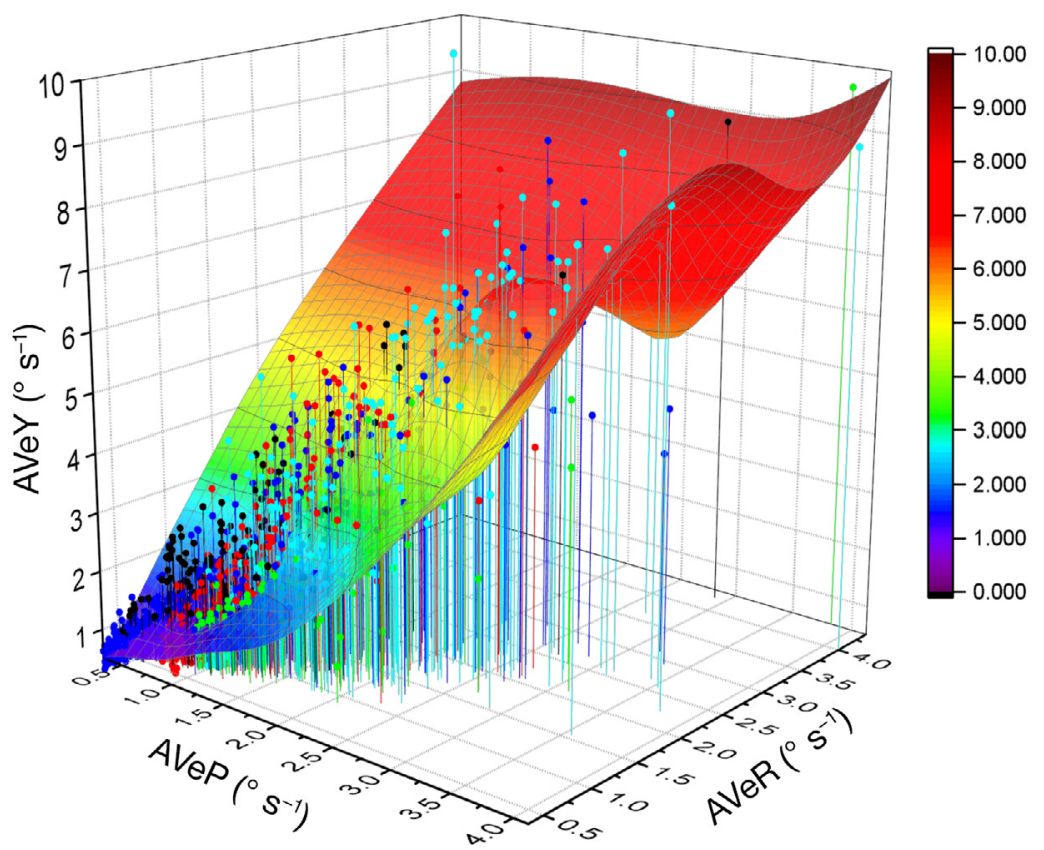

Fig. 4. Relationship between absolute values of angular velocity on all 3 axes (see Eq. 1). Each data point represents the mean value per dive. 3D colour map surface (coloured by AVeY) using a thin plated spline (smoothing of 1), constructed from a 3D gridding matrix. Projection of data points coloured according to turtle ID axes (Fig. 4). However, the rate change along the yaw axis was substantially greater than the other 2, approximately 2.5 times higher than the equivalent in pitch and roll (Fig. 4). We also noted, in a tri-axial plot of the extent of the 3 rotation metrics, how different individual turtles tended to occupy different sections of the envelope (Fig. 4).

The majority of time spent at the bottom was associated with resting, with individual values ranging from 62 to $84 \%$ (Fig. 5A). However, resting behaviour was rarely continuous over the duration of a single dive, with the bulk of dives incorporating intermittent bouts of rest and activity (Fig. 5C). Subclassification of dives into predominantly resting, active or episodic demonstrated this, with a high proportion of the dives (mean $( \pm$ SD) $50 \pm$ $22.5 \%$ ) showing patterns of activity lasting over $20 \%$ of the dive duration (Fig. 5B). There were also notable inter-individual differences in the proportion of time allocated to each dive status (Fig. 5B). The relative distribution of raw pitch, roll and yaw values differed between aggregated periods of rest and activity, with the latter generally showing greater variability (Fig. S2). There were, however, considerable offset differences between turtles in the unimodal peaks of density estimates for roll and pitch values (Fig. S2). 
A
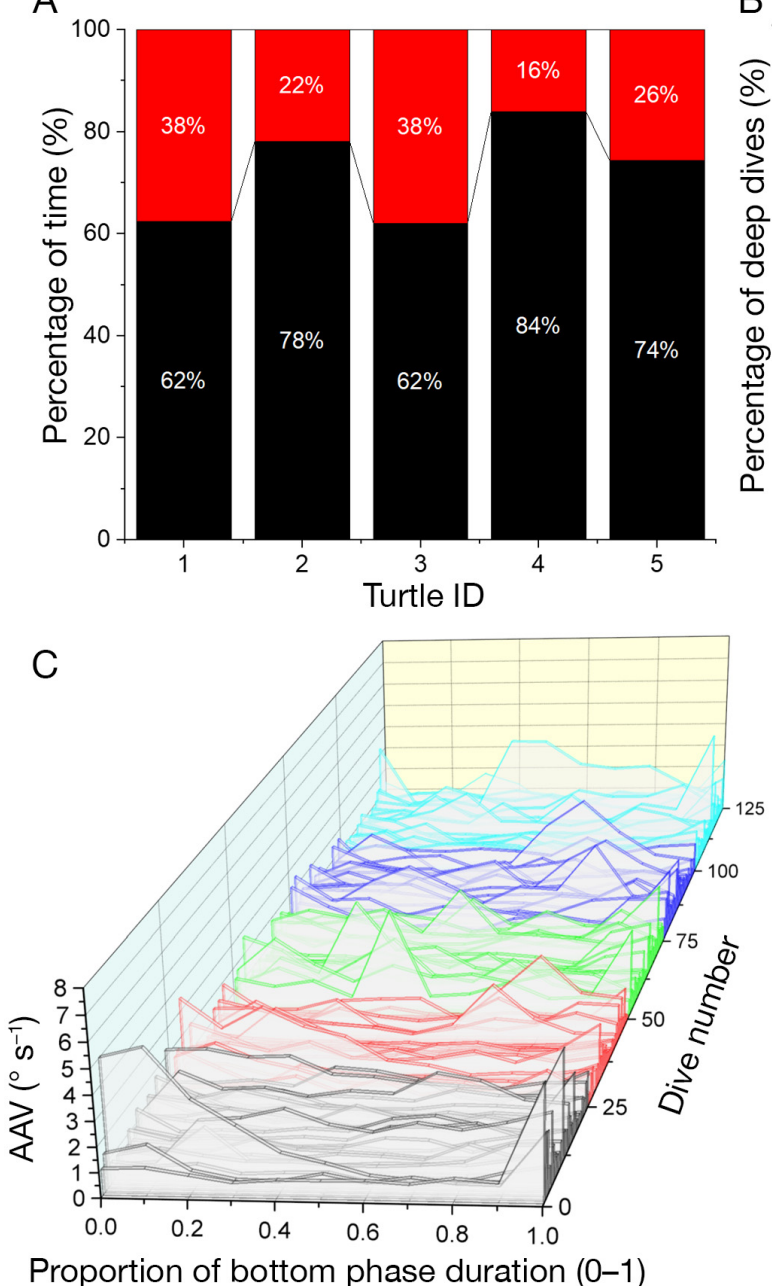

Proportion of bottom phase duration (0-1)

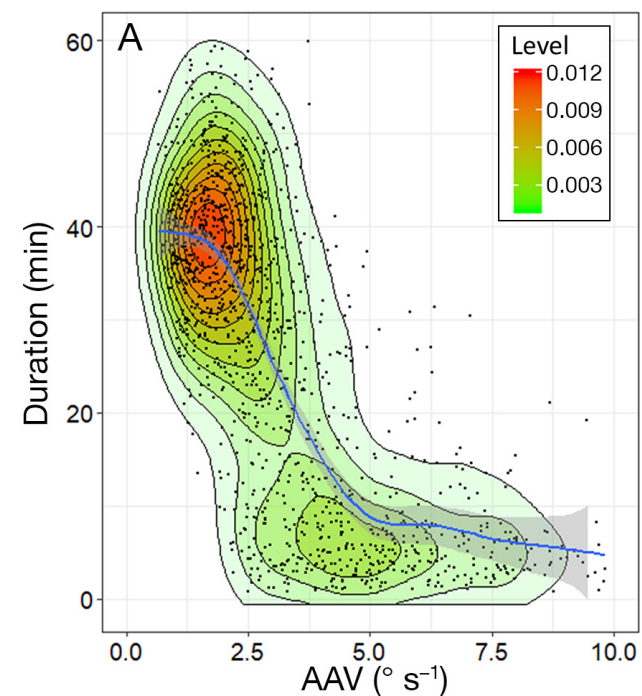

B

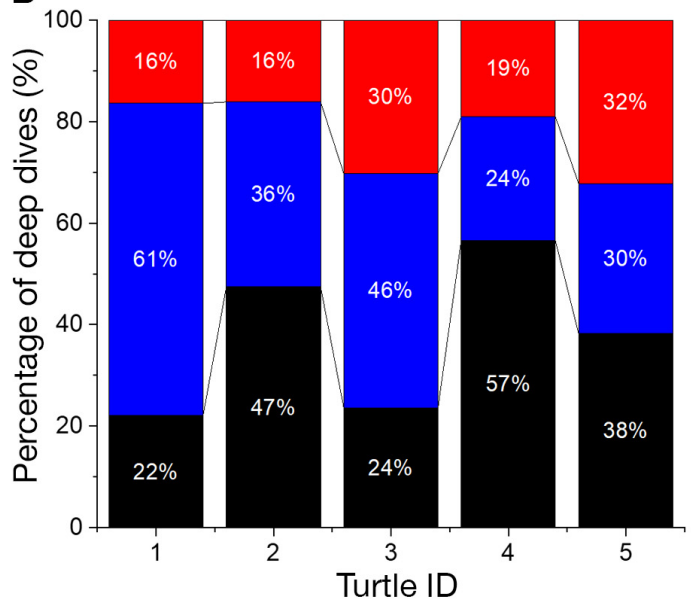

Fig. 5. Breakdown of individual activity budgets for each turtle. (A) Total bottom phase duration depicted as resting (black) and active (red). (B) Proportion of dives sub-classified as predominately: rest (black), episodic-rest (blue) and active (red). (C) Illustration of how absolute angular velocity (AAV) differed both within and between type 1a dives, showing mean AAV per 0.1 increment of bottom phase ( 0 to 1$)$, for 25 randomly selected dives per turtle. Lines coloured according to turtle ID

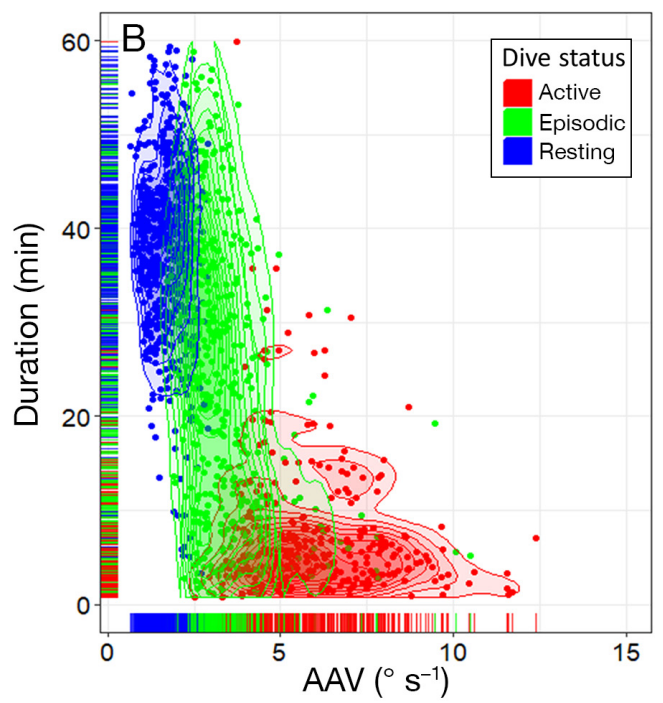

Fig. 6. (A) Relationship between absolute angular velocity (AAV) and dive duration; each data point represents the mean AAV value per dive. Contour plot showing the kernel density level of aggreged points and fitted with a line of best fit obtained from GAM smoothing (grey shading around line represents $95 \%$ confidence level interval). (B) Clustered polygon plot; points coloured according to the activity level of the dive (rest: red, episodic-rest: green and active: blue) and fitted with two 1-dimensional marginal rugs displaying individual case distributions 


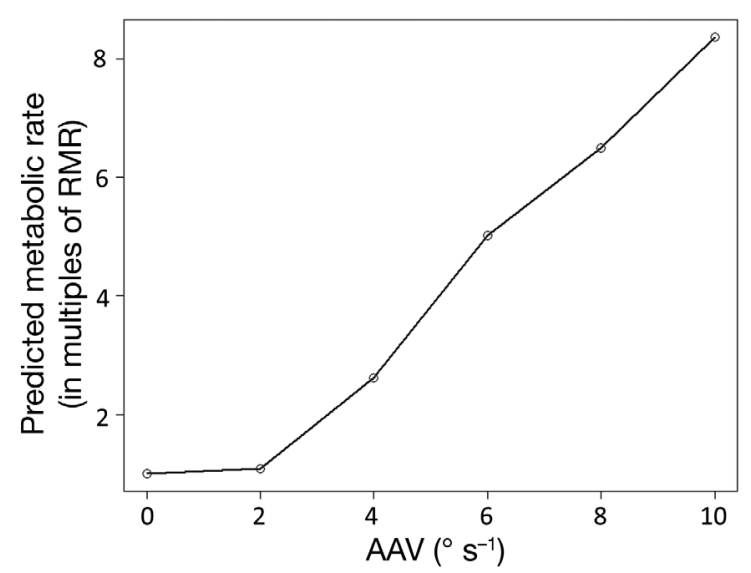

Fig. 7. Estimated metabolic costs (expressed as a multiple of resting metabolic rate [RMR]) associated with variation in absolute angular velocity (AAV). Estimated dive duration derived from GAM model (Table 1), divided by 40 min per 2-step increase in AAV $\left({ }^{\circ} \mathrm{s}^{-1}\right)$

There was a significant negative relationship between (log-transformed) AAV and bottom phase dive duration (LMM: $\left.\chi_{(1)}^{2}=1147, \mathrm{p}<0.01\right)$ (Fig. 6): for every $1 \%$ increase in $\mathrm{AAV}$, dive duration decreased by 0.25 (estimate $( \pm \mathrm{SE})=-24.86 \pm 0.58, \mathrm{t}=-43.20, \mathrm{p}<$ 0.001 ), suggesting that rotational activity resulted in shorter dives. Similarly, there was a significant negative relationship between (log-transformed) AVeY and bottom phase dive duration (LMM: $\chi^{2}{ }_{(1)}=1102$, $\mathrm{p}<0.01$; estimate $[ \pm \mathrm{SE}]=-17.49 \pm 0.42, \mathrm{t}=-42.01$, $\mathrm{p}<0.001)$ although the strength of the relationship was lower: AIC values were higher and coefficient of determination ( $\mathrm{R}^{2}$ values) were lower than for AAV $\left(\mathrm{AIC}=9576\right.$ and 9530 respectively; $\mathrm{R}_{\mathrm{c}}^{2}=0.63$ and 0.66 respectively). The significance of the AAV model was echoed by data fitted with a GAM model. Predicted multiples of RMR appeared to increase in a linear fashion relative to AAV (Fig. 7). Depth was not correlated with dive duration (estimate $[ \pm \mathrm{SE}]=1.28 \pm$ $1.43, t=0.90, p=0.37$ ) and the interactive effect between depth and dive duration was also non-significant (estimate $[ \pm \mathrm{SE}]=-2.24 \pm 2.30, \mathrm{t}=-0.97, \mathrm{p}=$ 0.33). See Table $\mathrm{S} 1$ for all model parameters.

\section{DISCUSSION}

\subsection{AAV and its ability to infer activity in turtles}

\subsubsection{Comparison between acceleration- and angular velocity-derived metrics}

Measures of acceleration are useful for quantifying animal activity (Brown et al. 2013, Wilmers et al.
2015). Indeed, dynamic body acceleration seems a reliable proxy for movement costs (Wilson et al. 2006, 2020a, Qasem et al. 2012). However, for slow-moving animals, acceleration can be negligible for extended periods (cf. Williams et al. 2017, Gunner et al. 2020), making dynamic acceleration a poor metric for activity (Wilson et al. 2020a). Despite this, and the extremely low VeDBA estimates in our turtles generally, mean values of VeDBA did increase over the 3 categories of resting, episodic-resting and active dives for each turtle (Fig. S3). However, the large offsets in VeDBA estimates between turtles, presumed to be due to differing tag placements on the animals (Wilson et al. 2020a), makes inter-individual comparisons problematic. In contrast, and critically, angular rotation across all 3 axes is not affected by site of placement of the tag on the carapace (within limits; see Text S1), so that angular velocity is a more standardised metric than dynamic body acceleration for interindividual comparisons (Wilson et al. 2020a). A further advantage of AAV as a general activity metric is that it considers all 3 rotation axes equally, providing a relative magnitude of rotation per $s$ that offers information about any sort of rotation.

AAV values are, however, not always due to rotations instigated by the animal (cf. Halsey et al. 2011). In the marine environment, for example, waves at the sea surface, as well as variations in underwater current vectors, probably apply rotational forces to animals. Similarly, passive descents of the water column, such as 'drift dives' by northern elephant seals Mirounga angustirostris, can result in body rotations (Mitani et al. 2010) and a similar process may operate in species that have passive ascents. However, although such things need to be borne in mind when considering AAV metrics, the effects are likely to be small compared to animal-instigated body rotations.

\subsubsection{Potential for AAV metrics to elucidate turtle behaviour}

Overall, the AAV metric resulting from combining the angular rotation about all 3 axes seems to be a sensitive proxy for depicting changes between active and inactive states in species that have low dynamism in their movement. Beyond this, we expect the contribution of the angular velocity from each rotational axis to vary (Fig. 4) according to behaviourspecific movements. For example, axis-linked angular velocity should vary between turtles changing heading while travelling (or not) along the seabed vs. animals travelling up and down the water column 
and this may have accounted, in part, for the variation in the position of individual turtles in the AVeY/ AVeP/AVeR envelope (Fig. 4). In future work, detailed studies of behaviour using video systems (e.g. Seminoff et al. 2006, Jeantet et al. 2018, 2020) combined with DD-type tags, could code observed behaviours in terms of axis-specific angular rotations. The findings could then be used to differentiate behaviours for individuals not equipped with video systems over much longer periods and at night.

However, even using AAV as a summary metric for general turtle activity seems to have appreciable value, not least due to the fine temporal scales over which angular rotation can be calculated. In our study, increased rotational activity is probably related, to some degree, to foraging. However, based on our findings, we suggest that the utility of AAV could be expanded to investigate turtle activity levels across different dive types (see, for example, those detailed by Hochscheid [2014]). This metric may prove particularly useful for slow-moving animals in general because small variations in AAV can provide the resolution required to distinguish activity from inactivity, itself an important biomarker for understanding energy expenditure and even health (cf. Arkwright et al. 2020).

\subsection{BEHAVIOUR DURING DIVES}

\subsubsection{Depth use}

Sea turtles show complex diving patterns, each characteristic dive pattern associated with specific behaviours. Type 1a dives are generally considered important for facilitating bouts of benthic rest, most particularly in nesting females that have to manage energy reserves in order to maximize egg development (e.g. Wallace et al. 2005, Walcott et al. 2012).

Bathymetry estimates at Boa Vista beach showed that bottom depth can be $<8 \mathrm{~m}$ at distances greater than $3 \mathrm{~km}$ from the nesting beach (Fig. S1). Given the relatively low percentage of time that turtles dived deeper than $3 \mathrm{~m}$, the shallow depths obtained during type 1a dives and the relatively high occurrence of this dive type throughout the inter-nesting interval (Fig. 3B, Table 1), it is highly probable that the turtles spent the bulk of their time close to the coast, or at least within shallow areas out at sea. This is similar to the results of previous studies, which have documented turtles often preferring to be near topographic features in shallow water. These features provide important microsites for cover, reducing sus- ceptibility to predation (Heithaus et al. 2002) and decreasing energetic costs by minimising current vectors which could otherwise disrupt motionless rest (Seminoff et al. 2006). Our results also seem to mirror those found for loggerhead turtles in Greece, where nesting females spend the most time in shallow waters that are likely to be warmer, to enhance incubation (Schofield et al. 2009).

\subsubsection{Activity extent of type 1a dives}

Given the focus on shallow depths in this study (cf. Table 1) (and only one dive type assessed), it is not surprising that we did not find a relationship between dive duration and depth, which has been repeatedly confirmed by multiple authors (e.g. Minamikawa et al. 1997, 2000, Hochscheid et al. 1999, Hays et al. $2000,2004)$. However, the consistency of dive depth shown by our turtles does make a case for them loading similar amounts of oxygen for their type 1a dives (Minamikawa et al. 2000). This helps minimize depth as a confounding effect in the data set. Specifically, assuming that turtles diving to a set depth do indeed submerge with comparable amounts of oxygen, when they are more active underwater, it should deplete oxygen stores faster, resulting in shorter dives. Indeed, this reasoning is why it has been suggested that dive duration can sometimes be used to infer metabolic rate (Hays et al. 2000, Enstipp et al. 2011).

In the current study we found that dive duration decreased with increasing rotational movement (mean AAV) over the bottom phase of type 1a dives (Fig. 6a). This agrees with past studies showing that energetic cost is related to activity and indicates that greater amounts of movement are indeed associated with higher power use (Enstipp et al. 2011, Halsey et al. 2011, Fahlman et al. 2013, J. W. Wilson et al. 2013, Zamparo et al. 2019). What our study adds that is new to this framework is the idea that rotational movement, rather than just linear acceleration as exemplified by DBA metrics (Enstipp et al. 2011, Halsey et al. 2011), appears to be a major modulator of oxygen consumption. As projected, it seems higher power use associated with rotation depletes oxygen stores at a faster rate, causing dives to be correspondingly curtailed. We estimate that turtles could increases their metabolic rate by up to 8 times RMR during the bottom phase of type 1a dives in times of their most extreme AAV activity (Fig. 7).

This predicted increase in RMR presumably has general energetic consequences at a time when females are considered to be under strong selection 
pressure to be judicious with their reserves during initial egg gestation. Displaying appreciable activity would seem to conflict with the argument that energy conservation should be a prime modulator of fitness for female sea turtles (Hays et al. 2002a, Hopkins-Murphy et al. 2003, Schofield et al. 2006). Such an increase in energy expenditure could be justified, however, if it were to result in a net gain of energy via local feeding around the nesting sites. Based on this, we suggest that, although turtles may rotate for a number of reasons, such as to react to predators (Heithaus et al. 2002) or conspecifics (Schofield et al. 2007), the AAV metrics from our study predominantly indicate local supplementary foraging of nesting turtles.

This inference is supported to some extent (1) by results obtained via animal-borne video cameras and movement-based sensors deployed elsewhere (e.g. Hochscheid \& Wilson 1999, Schofield et al. 2006, Seminoff et al. 2006, Houghton et al. 2008, Fossette et al. 2010) and (2) indirectly by known change in stable isotope values over the nesting season in this population (Cameron et al. 2019). Certainly, captive loggerheads rotate their bodies appreciably during feeding (Wilson et al. 2020c) as they deal with their prey, which for wild animals consists primarily of crustaceans, gastropods and echinoids (Bjorndal 2003), and the peaks we observed in AAV (Fig. 5C) may be due to this. These predominantly benthic food items would require turtles to maintain a constant depth, a critical criterion for type 1a dives. All this ties in with Hochscheid et al.'s (1999) study, where they noted appreciable angular body movement in 2 inter-nesting green turtles off Cyprus, from which they deduced that $34 \%$ of the time budget of these animals was spent foraging. A notable point made in Hochscheid et al.'s (1999) study was that the inter-nesting area frequented by their animals was extensively covered by sea grass, the primary food of green turtles (Hays et al. 2002b, Lemons et al. 2011, Heithaus et al. 2014), so there was ample opportunity to feed.

Although our results coupled with those of Hochscheid et al. (1999) only amount to data from 7 animals (of 2 different species), they do suggest that female turtles may forage between nesting events. If true, this hasimplications for area management. For example, it may indicate that protection of resources, e.g. by minimizing exploitation around the nesting site, is important to allow females to maintain body condition at this critical time.

Acknowledgements. This research contributes to the CAASE project funded by King Abdullah University of Science and
Technology (KAUST) under the KAUST Sensor Initiative. The fieldwork was funded by a grant (CP1217) awarded to R.S. from the Cluster of Excellence 80 The Future Ocean. The Future Ocean was funded within the framework of the Excellence Initiative by the Deutsche Forschungsgemeinschaft (DFG) on behalf of the German federal and state governments. This work was part of the Turtle Project created by C.E. and partly funded by National Geographic (GEFNE69-13), The Whitley Wildlife Conservation Trust and 'The Future Ocean' through a Capacity Building grant to C.E. We also acknowledge support from the Direção Nacional do Ambiente Cabo Verde.

\section{LITERATURE CITED}

Arkwright AC, Archibald E, Fahlman A, Holton MD and others (2020) Behavioral biomarkers for animal health: a case study using animal-attached technology on loggerhead turtles. Front Ecol Evol 7:504

Bates D, Mächler M, Bolker B, Walker S (2015) Fitting linear mixed-effects models using lme4. J Stat Softw 67:1-48

Bjorndal KA (2003) Roles of loggerhead sea turtles in marine ecosystems. Smithsonian Books, Washington, DC

Bonnet X, Bradshaw D, Shine R (1998) Capital versus income breeding: an ectothermic perspective. Oikos 83: 333-342

Brown DD, Kays R, Wikelski M, Wilson R, Klimley AP (2013) Observing the unwatchable through acceleration logging of animal behavior. Anim Biotelem 1:20

Butt N, Whiting S, Dethmers K (2016) Identifying future sea turtle conservation areas under climate change. Biol Conserv 204:189-196

* Cameron SJK, Baltazar-Soares M, Stiebens VA, Reischig T, Correia SM, Harrod C, Eizaguirre C (2019) Diversity of feeding strategies in loggerhead sea turtles from the Cape Verde archipelago. Mar Biol 166:130

Cheng I-J (2009) Changes in diving behaviour during the internesting period by green turtles. J Exp Mar Biol Ecol 381:18-24

* Dodge KL, Kukulya AL, Burke E, Baumgartner MF (2018) TurtleCam: a 'smart' autonomous underwater vehicle for investigating behaviors and habitats of sea turtles. Front Mar Sci 5:90

* Eckert SA (2002) Swim speed and movement patterns of gravid leatherback sea turtles (Dermochelys coriacea) at St Croix, US Virgin Islands. J Exp Biol 205:3689-3697

Eckert SA, Nellis DW, Eckert KL, Kooyman GL (1986) Diving patterns of two leatherback sea turtles (Dermochelys coriacea) during internesting intervals at Sandy Point, St. Croix, U.S. Virgin Islands. Herpetologica 42:381-388

Enstipp MR, Ciccione S, Gineste B, Milbergue M and others (2011) Energy expenditure of freely swimming adult green turtles (Chelonia mydas) and its link with body acceleration. J Exp Biol 214:4010-4020

Fahlman A, Svärd C, Rosen DAS, Wilson RP, Trites AW (2013) Activity as a proxy to estimate metabolic rate and to partition the metabolic cost of diving vs. breathing in pre- and post-fasted Steller sea lions. Aquat Biol 18:175-184

* Fossette S, Gleiss AC, Myers AE, Garner S and others (2010) Behaviour and buoyancy regulation in the deepest-diving reptile: the leatherback turtle. J Exp Biol 213:4074-4083

Gilman E, Moth-Poulsen T, Bianchi G (2007) Review of measures taken by intergovernmental organizations to address sea turtle and seabird interactions in marine cap- 
ture fisheries. FAO Fisheries Circular No. 1025. Food and Agriculture Organization of the United Nations, Rome

* Greggor AL, Berger-Tal O, Blumstein DT, Angeloni L and others (2016) Research priorities from animal behaviour for maximising conservation progress. Trends Ecol Evol 31:953-964

* Gunner RM, Wilson RP, Holton MD, Scott R, Hopkins P, Duarte CM (2020) A new direction for differentiating animal activity based on measuring angular velocity about the yaw axis. Ecol Evol 10:7872-7886

Halsey LG, Jones TT, Jones DR, Liebsch N, Booth DT (2011) Measuring energy expenditure in sub-adult and hatchling sea turtles via accelerometry. PLOS ONE 6:e22311

*Hart KM, Zawada DG, Fujisaki I, Lidz BH (2010) Inter-nesting habitat-use patterns of loggerhead sea turtles: enhancing satellite tracking with benthic mapping. Aquat Biol 11:77-90

Hays GC (2008) Sea turtles: a review of some key recent discoveries and remaining questions. J Exp Mar Biol Ecol 356:1-7

Hays GC, Hochscheid S, Broderick A, Godley B, Metcalfe J (2000) Diving behaviour of green turtles: dive depth, dive duration and activity levels. Mar Ecol Prog Ser 208: 297-298

* Hays GC, Broderick AC, Glen F, Godley BJ, Houghton JDR, Metcalfe JD (2002a) Water temperature and internesting intervals for loggerhead (Caretta caretta) and green (Chelonia mydas) sea turtles. J Therm Biol 27:429-432

Hays GC, Glen F, Broderick AC, Godley BJ, Metcalfe JD (2002b) Behavioural plasticity in a large marine herbivore: contrasting patterns of depth utilisation between two green turtle (Chelonia mydas) populations. Mar Biol 141:985-990

Hays GC, Metcalfe JD, Walne AW (2004) The implications of lung-regulated buoyancy control for dive depth and duration. Ecology 85:1137-1145

Hays GC, Marshall GJ, Seminoff JA (2007) Flipper beat frequency and amplitude changes in diving green turtles, Chelonia mydas. Mar Biol 150:1003-1009

*Heithaus M, Frid A, Dill L (2002) Shark-inflicted injury frequencies, escape ability, and habitat use of green and loggerhead turtles. Mar Biol 140:229-236

*Heithaus MR, Alcoverro T, Arthur R, Burkholder DA and others (2014) Seagrasses in the age of sea turtle conservation and shark overfishing. Front Mar Sci 1:28

Hochscheid S (2014) Why we mind sea turtles' underwater business: a review on the study of diving behavior. J Exp Mar Biol Ecol 450:118-136

Hochscheid S, Wilson RP (1999) A new method for the determination of at-sea activity in sea turtles. Mar Ecol Prog Ser 185:293-296

*Hochscheid S, Godley BJ, Broderick AC, Wilson RP (1999) Reptilian diving: highly variable dive patterns in the green turtle Chelonia mydas. Mar Ecol Prog Ser 185:101-112

*Hochscheid S, Bentivegna F, Bradai MN, Hays GC (2007) Overwintering behaviour in sea turtles: dormancy is optional. Mar Ecol Prog Ser 340:287-298

Hopkins-Murphy S, Owens D, Murphy T (2003) Ecology of immature loggerheads on foraging grounds and adults in internesting habitat in the eastern United States, Vol 1. Smithsonian Institution Press, Washington, DC

Houghton JD, Broderick AC, Godley BJ, Metcalfe JD, Hays GC (2002) Diving behaviour during the internesting interval for loggerhead turtles Caretta caretta nesting in Cyprus. Mar Ecol Prog Ser 227:63-70
Houghton JDR, Doyle TK, Davenport J, Wilson RP, Hays GC (2008) The role of infrequent and extraordinary deep dives in leatherback turtles (Dermochelys coriacea). J Exp Biol 211:2566-2575

Hussey NE, Kessel ST, Aarestrup K, Cooke SJ and others (2015) Aquatic animal telemetry: a panoramic window into the underwater world. Science 348:1255642

Jeantet L, Dell'Amico F, Forin-Wiart MA, Coutant M and others (2018) Combined use of two supervised learning algorithms to model sea turtle behaviours from tri-axial acceleration data. J Exp Biol 221:jeb177378

* Jeantet L, Planas-Bielsa V, Benhamou S, Geiger S and others (2020) Behavioural inference from signal processing using animal-borne multi-sensor loggers: a novel solution to extend the knowledge of sea turtle ecology. R Soc Open Sci 7:200139

* Jönsson KI (1997) Capital and income breeding as alternative tactics of resource use in reproduction. Oikos 78:57-66

Kemons G, Lewison R, Komoroske L, Gaos A and others (2011) Trophic ecology of green sea turtles in a highly urbanized bay: insights from stable isotopes and mixing models. J Exp Mar Biol Ecol 405:25-32

López-Sepulcre As (2007) The evolutionary ecology of space use and its conservation consequences. Jyväskylä studies in biological and environmental science, Vol 172. University of Jyväskylä

Martin C (2003) The behaviour of free-living marine turtles: underwater activities, migrations and seasonal occurrences. PhD thesis, University of Wales, Swansea

* Minamikawa S, Naito Y, Uchida I (1997) Buoyancy control in diving behavior of the loggerhead turtle, Caretta caretta. J Ethol 15:109-118

Minamikawa S, Naito Y, Sato K, Matsuzawa Y, Bando T, Sakamoto W (2000) Maintenance of neutral buoyancy by depth selection in the loggerhead turtle Caretta caretta. J Exp Biol 203:2967-2975

Mingozzi T, Mencacci R, Cerritelli G, Giunchi D, Luschi P (2016) Living between widely separated areas: longterm monitoring of Mediterranean loggerhead turtles sheds light on cryptic aspects of females spatial ecology. J Exp Mar Biol Ecol 485:8-17

Mitani Y, Andrews RD, Sato K, Kato A, Naito Y, Costa DP (2010) Three-dimensional resting behaviour of northern elephant seals: drifting like a falling leaf. Biol Lett 6: 163-166

* Myers AE, Hays GC (2006) Do leatherback turtles Dermochelys coriacea forage during the breeding season? A combination of data-logging devices provide new insights. Mar Ecol Prog Ser 322:259-267

Narazaki T, Sato K, Abernathy K, Marshall G, Miyazaki N (2009) Sea turtles compensate deflection of heading at the sea surface during directional travel. J Exp Biol 212: 4019-4026

Noda T, Okuyama J, Koizumi T, Arai N, Kobayashi M (2012) Monitoring attitude and dynamic acceleration of freemoving aquatic animals using a gyroscope. Aquat Biol 16:265-276

* Okuyama J, Shimizu T, Abe O, Yoseda K, Arai N (2010) Wild versus head-started hawksbill turtles Eretmochelys imbricata: post-release behavior and feeding adaptions. Endang Species Res 10:181-190

\% Okuyama J, Kataoka K, Kobayashi M, Abe O, Yoseda K, Arai $N$ (2012) The regularity of dive performance in sea turtles: a new perspective from precise activity data. Anim Behav 84:349-359 
Ozyagcilar T (2012) Implementing a tilt-compensated eCompass using accelerometer and magnetometer sensors. Application Note AN4248. Freescale Semiconductor, Austin, TX

Park S, Aschenbach KH, Ahmed M, Scott WL and others (2019) Animal-borne wireless network: remote imaging of community ecology. J Field Robot 36:1141-1165

Parlin AF, Nardone JA, Kelly Dougherty J, Rebein M, Safi K, Schaeffer PJ (2018) Activity and movement of free-living box turtles are largely independent of ambient and thermal conditions. Mov Ecol 6:12

Pedley M (2012) eCompass: build and calibrate a tilt-compensating electronic compass. Circuit Cellar 265:1-6

Pedley M (2013) Tilt sensing using a three-axis accelerometer. Application Note AN3461. Freescale Semiconductor. www.nxp.com/docs/en/application-note/AN3461.pdf (accessed April 2021)

Pewsey A, Neuhäuser M, Ruxton GD (2013) Circular statistics in R. Oxford University Press, Oxford

Plot V, Jenkins T, Robin JP, Fossette S, Georges JY (2013) Leatherback turtles are capital breeders: morphometric and physiological evidence from longitudinal monitoring. Physiol Biochem Zool 86:385-397

Qasem L, Cardew A, Wilson A, Griffiths I and others (2012) Tri-axial dynamic acceleration as a proxy for animal energy expenditure; should we be summing values or calculating the vector? PLOS ONE 7:e31187

Rice MR, Balazs GH (2008) Diving behavior of the Hawaiian green turtle (Chelonia mydas) during oceanic migrations. J Exp Mar Biol Ecol 356:121-127

Schofield G, Katselidis KA, Dimopoulos P, Pantis JD, Hays GC (2006) Behaviour analysis of the loggerhead sea turtle Caretta caretta from direct in-water observation. Endang Species Res 2:71-79

Schofield G, Katselidis KA, Pantis JD, Dimopoulos P, Hays GC (2007) Female-female aggression: structure of interaction and outcome in loggerhead sea turtles. Mar Ecol Prog Ser 336:267-274

Schofield G, Bishop CM, Katselidis KA, Dimopoulos P, Pantis JD, Hays GC (2009) Microhabitat selection by sea turtles in a dynamic thermal marine environment. J Anim Ecol 78:14-21

Seminoff JA, Jones TT, Marshall GJ (2006) Underwater behaviour of green turtles monitored with video-timedepth recorders: what's missing from dive profiles? Mar Ecol Prog Ser 322:269-280

Tuck K (2010) How many bits are enough? The trade-off between high resolution and low power using oversampling modes. Application Note AN4075. Freescale Semiconductor, Tempe, AZ

Walcott J, Eckert S, Horrocks J (2012) Tracking hawksbill sea turtles (Eretmochelys imbricata) during inter-nesting intervals around Barbados. Mar Biol 159:927-938

Walker JA, Westneat MW (2000) Mechanical performance

Editorial responsibility: Brendan Godley,

University of Exeter, Cornwall Campus, UK

Reviewed by: 3 anonymous referees of aquatic rowing and flying. Proc R Soc B 267: 1875-1881

*Wallace BP, Williams CL, Paladino FV, Morreale SJ, Lindstrom RT, Spotila JR (2005) Bioenergetics and diving activity of internesting leatherback turtles Dermochelys coriacea at Parque Nacional Marino Las Baulas, Costa Rica. J Exp Biol 208:3873-3884

Wallace BP, Zolkewitz M, James MC (2015) Fine-scale foraging ecology of leatherback turtles. Front Ecol Evol 3:15

* Williams HJ, Holton MD, Shepard ELC, Largey N and others (2017) Identification of animal movement patterns using tri-axial magnetometry. Mov Ecol 5:6

Wilmers CC, Nickel B, Bryce CM, Smith JA, Wheat RE, Yovovich V (2015) The golden age of bio-logging: how animal-borne sensors are advancing the frontiers of ecology. Ecology 96:1741-1753

*Wilson AM, Lowe J, Roskilly K, Hudson PE, Golabek K, McNutt J (2013) Locomotion dynamics of hunting in wild cheetahs. Nature 498:185-189

*Wilson JW, Mills MG, Wilson RP, Peters G and others (2013) Cheetahs, Acinonyx jubatus, balance turn capacity with pace when chasing prey. Biol Lett 9:20130620

*Wilson M, Tucker AD, Beedholm K, Mann DA (2017) Changes of loggerhead turtle (Caretta caretta) dive behavior associated with tropical storm passage during the inter-nesting period. J Exp Biol 220:3432-3441

*Wilson RP, Hustler K, Ryan PG, Burger AE, Noldeke EC (1992) Diving birds in cold water: do Archimedes and Boyle determine energetic costs? Am Nat 140:179-200

*Wilson RP, White CR, Quintana F, Halsey LG, Liebsch N, Martin GR, Butler PJ (2006) Moving towards acceleration for estimates of activity-specific metabolic rate in free-living animals: the case of the cormorant. J Anim Ecol 75:1081-1090

Wilson RP, Shepard E, Liebsch N (2008) Prying into the intimate details of animal lives: use of a daily diary on animals. Endang Species Res 4:123-137

Wilson RP, Börger L, Holton MD, Scantlebury DM and others (2020a) Estimates for energy expenditure in freeliving animals using acceleration proxies: a reappraisal. J Anim Ecol 89:161-172

Wilson RP, Rose KAR, Metcalfe RS, Holton MD and others (2020b) Path tortuosity changes the transport cost paradigm in terrestrial animals. bioRxiv preprint, doi:10.1101/ 2020.08.20.259390

Wilson RP, Williams HJ, Holton MD, di Virgilio A and others (2020c) An 'orientation sphere' visualization for examining animal head movements. Ecol Evol 10:4291-4302

Wyneken J (1997) Sea turtle locomotion: mechanics, behavior, and energetics. CRC Press, Boca Raton, FL

* Zamparo P, Pavei G, Monte A, Nardello F and others (2019) Mechanical work in shuttle running as a function of speed and distance: implications for power and efficiency. Hum Mov Sci 66:487-496

Submitted: September 12, 2019

Accepted: March 12, 2021

Proofs received from author(s): April 19, 2021 